\title{
Aleksandr I. Andreev, Dany Savelli (éd.), Rerihi. Mify i fakty. Sbornik statej / Les Roerich entre mythes et faits / The Roerichs: Myths and facts
}

Saint-Pétersbourg, Nestor-Istorija, 2011, 311 p., ill.

Françoise Aubin

\section{OpenEdition}

Journals

Édition électronique

URL : http://journals.openedition.org/assr/23904

DOI : $10.4000 /$ assr.23904

ISSN : $1777-5825$

Éditeur

Éditions de l'EHESS

Édition imprimée

Date de publication : 30 décembre 2012

Pagination : 108

ISSN : 0335-5985

Référence électronique

Françoise Aubin, «Aleksandr I. Andreev, Dany Savelli (éd.), Rerihi. Mify i fakty. Sbornik statej / Les Roerich entre mythes et faits / The Roerichs : Myths and facts ", Archives de sciences sociales des religions [En ligne], 160 | octobre-décembre 2012, mis en ligne le 21 février 2013, consulté le 21 septembre 2020. URL : http://journals.openedition.org/assr/23904; DOI : https://doi.org/10.4000/ assr.23904

Ce document a été généré automatiquement le 21 septembre 2020.

(C) Archives de sciences sociales des religions 


\section{Aleksandr I. Andreev, Dany Savelli (éd.), Rerihi. Mify i fakty. Sbornik statej / Les Roerich entre mythes et faits / The Roerichs : Myths and facts}

Saint-Pétersbourg, Nestor-Istorija, 2011, 311 p., ill.

Françoise Aubin

\section{RÉFÉRENCE}

Aleksandr I. Andreev, Dany Savelli (éd.), Rerihi. Mify i fakty. Sbornik statej / Les Roerich entre mythes et faits / The Roerichs : Myths and facts. Saint-Pétersbourg, Nestor-Istorija, 2011, 311 p., ill. 
1 Voici un ouvrage publié en russe à StPétersbourg en collaboration avec des institutions françaises et par une coéditrice française, Dany Savelli, de l'Université de Toulouse. La collaboration en est internationale (le coéditeur Aleksandr Andreev est de St-Pétersbourg et deux auteurs viennent de Moscou; outre Savelli, une collaboratrice est une slavophone installée en France; on trouve également un Canadien; un Japonais de Tokyo et deux Lettons). Le public visé est, certes, russophone d'abord, mais sans

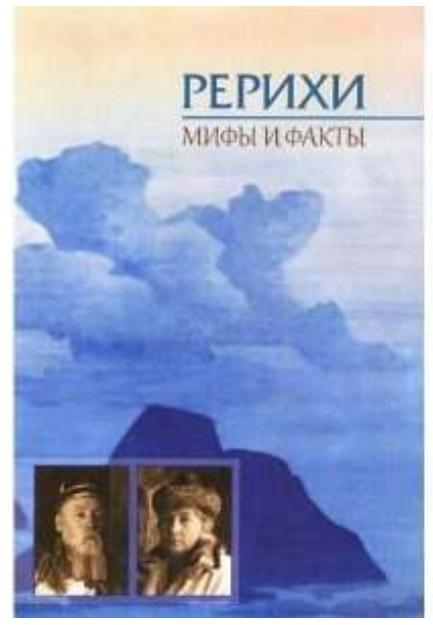
contredit international lui aussi, comme en témoignent les résumés substantiels en français et en anglais (les articles étant donnés par ordre du contenu, alors que les résumés le sont par ordre alphabétique des noms d'auteur, que les résumés anglais diffèrent légèrement des résumés français et que manque le titre courant des articles, je citerai pour chaque contribution la pagination de l'article, suivie de la pagination du résumé français puis du résumé anglais, afin qu'un lecteur intéressé puisse commander les photocopies qui lui conviennent). Pour le public cultivé russe le nom de «Rerikh » (= Roerich) évoque tout un mouvement théosophe encore vivant. Mais il est douteux qu'en Occident l'on soit aussi familier avec les noms et l'œuvre des membres de la famille : une petite notice biographique aurait été la bienvenue, avec les dates des voyages et des engagements des Roerich (le russophone peut se référer à la Bol'shaya Sovetskaya Enciklopedya, par

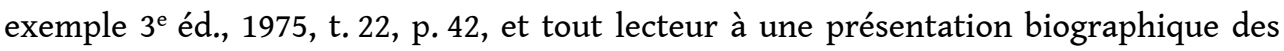
activités et orientations idéologiques des personnages jusqu'en 1928, dans un article dont l'éditeur est précisément D. Savelli : Slavica Occitana, Toulouse, XXI, 2005, p. 243-263, par Vladimir A. Rosov). Tout juste une petite note, en russe en page de garde et in fine en anglais p. 311, nous apprend que les héros de l'histoire sont Nikolaï [Konstantinovich] Roerich (1874-1947), peintre, écrivain, voyageur, et sa femme, épousée en 1901, Elena, née Shaposhnikova (1879-1955). Finalement, à la lecture du présent ouvrage, on connaît mieux les ancêtres de Nikolaï Roerich que lui-même, car dans un article, réjouissant pour qui se souvient des éloges qui ont été décernés à la noble origine du personnage même en Union soviétique, Ivars Silars (p. 8-29, rés. fr. 296, rés. angl. 306) démontre, archives à l'appui, que les Roerich ne descendent pas du héros fondateur de la Rus', Riurik, mais sont originaires de Kurzeme/Courlande (Lettonie), que Konstantin, le père de Nikolaï, est l'enfant naturel d'une domestique, qu'il a été adopté par Friedrich Roerich, l'intendant de la propriété appartenant aux parents de son père biologique, et que ce Friedrich était lui-même fils d'un couturier et petit-fils d'un cordonnier.

2 Le premier volet de la saga des Roerich concerne l'esthétique picturale de Nikolaï : il aurait d'abord consciemment utilisé des techniques dites « kitsch » et « tape-à-l'œil »; puis après le tournant prophétique de son enseignement à la fin des années $1910 \mathrm{du} \mathrm{xx}$ siècle, l'exotisme oriental serait devenu son mode d'expression artistique (Nadia Chtchetkina-Rocher, p. 30-56, rés. fr. 293, rés. angl. 303). La contribution d'Andreev touche ensuite à l'essentiel du sujet : la prise de position de Nikolaï et de sa femme 
Elena comme gourous, dans les années 1920 et 1930 : fondateurs d'une quasi-religion, l'Agni Yoga, ils développent un "Grand Plan" d'édification d'un monde idéal, un Shambala terrestre intégrant les États-Unis, la Russie, l'Inde et le Tibet, sous l'inspiration du " Maître de l'au-delà », le Mahatma Morya, un monde occulte qu'Elena décrit dans un flot de livres et Nikolaï dans des vues débouchant sur « l'autre monde " (p. 57-107, rés. fr. 291-292, rés. angl. 301-302). En contre-point, nous avons la vision de l'action des Roerich par celle qui fut leur plus proche collaboratrice de 1929 à la dissolution du "Cercle » ésotérique de New York en 1935, et qui séjourna avec eux en Inde, à Kulu, en 1929-31 et en 1934, Esther Lichtman/Lichtmann (1892-1990), d'après les mille cinq cents pages de notes quotidiennes en russe et en anglais qu'elle a laissées (encore par A. Andreev, p. 108-154, rés. fr. 292-293, rés. angl. 302-303).

3 Nikolaï dit qu'entre 1929 et 1930, ont été créées quarante-cinq sociétés faisant allégeance à ses théories. Dany Savelli narre, d'après la correspondance de responsables de l'aventure, l'apparition à Paris en juin 1929 de l'Association française des Amis du Roerich Museum (antenne du Musée Roerich fondé à New York en 1923), ses liens avec l'émigration russe, ses tentatives d'intégration dans la vie politique française et son échec final en 1935, causé tant par ses méthodes de travail que par la crise financière et politique mondiale ainsi que par les accusations de "bolchevisme» et de "francmaçonnerie » lancées contre Nikolaï (p. 155-195, rés. fr. 295-296, rés. angl. 305-306). Yukiko Kitamura remarque que les conditions du séjour de Nikolaï au Japon en 1934 restent mal connues et que les articles autochtones qui lui ont été consacrés jusqu'en 2006 l'envisagent comme un artiste original et nullement comme un penseur mystique combattant pour un nouvel ordre mondial (p. 196-310, article traduit du japonais en russe par Andreev, rés. fr. 294, rés. angl. 304). Un des fondements de l'engagement de Nikolaï fut son amour indéfectible pour la Russie. Mais son attitude à l'égard de l'Union soviétique varia au cours du temps : anti-soviétisme jusqu'au début des années 1920 et dans la seconde moitié des années 1930, pro-soviétisme entre-temps et à partir de 1937. Selon John McCannon, les tableaux peints par l'artiste durant la Seconde Guerre mondiale sont autant de (vaines) déclarations de loyauté au régime en place (p. 211-234, rés. fr. 294-295, rés. angl. 304-305).

4 Enfin ce qu'il est convenu d'appeler «le mouvement Rerikh/Roerich » s'est développé tout particulièrement, d'une part, dans la Russie postsoviétique où il a constitué un courant spirituel associant Orient, valeurs soviétiques, New Age (Roman Nikolaevich Lunkin \& Sergeï Borisovich Filatov, p. 235-258, rés. fr. 293-294, rés. angl. 303-304; de ces mêmes auteurs, on pourra lire un article solidement documenté en anglais, «The Rerikh Movement: A Homegrown Russian "New Religious Movement" ", Religion, State \& Society, XXVIII/1, 2000, p. 135-148); d'autre part, dans la Lettonie des ancêtres de Nikolaï, où, fondé dès 1920 à Riga comme "Loge du Maître ", ce fut là une de ses premières manifestations au monde et des plus actives dans les années 1930, puis, réanimé en 1988 et scindé en trois entités, il cherche à influencer maintenant la culture, l'éducation et la vie politique de la Lettonie (Anita Stasulane, p. 259-279, rés. fr. 297, rés. angl. 307).

5 Ces neuf passionnants articles, qui s'intègrent autant dans l'histoire du mysticisme russe parmi les émigrés de l'époque communiste et sur place depuis la chute du régime, que dans les études sur l'occultisme, la théosophie, le New Age à travers le monde, mériteraient une publication accessible aux non-russophones: on aimerait avoir les articles originaux écrits en français et en anglais, et une traduction française ou 
anglaise des articles russes, lettons et japonais. Suggérons aussi aux éditeurs de choisir, pour le confort du lecteur, une typographie plus lisible pour les notes, agréablement informatives, des titres courants en haut de chaque page, un index. Et pourquoi pas une petite notice biographique des héros de l'histoire, le couple Nikolaï-Elena, par exemple sous forme de chronologie, ainsi que quelques rappels qui éclaireraient le lecteur, à savoir, par exemple, que la chorégraphie à scandale du Sacre du printemps de Stravinsky a été imaginée par Nikolaï, qui a également été célèbre en son temps pour ses peintures représentant une ancienne Russie païenne idéalisée et pour sa conception de l'archéologie comme un culte extatique à la terre; que sa biographie a déjà été publiée en anglais et en français (Jacqueline Decter, Nicholas Roerich: The Life and Art of a Russian Master, Rochester, Vt : Park Street Press, 1989 ; ou Nicolas Roerich. La vie et l'œuvre d'un maitre russe, trad. de l'anglais, Sherbrooke, Belize : Éd. du II millénaire, 1990); que son fils cadet Sviatoslav Nikolaevich (1904-1993, dont la femme épousée en 1945, Devika Rani, était une célèbre actrice dans les films indiens des années 1930) a été, lui aussi, un peintre renommé ; et que, surtout, le grand maître russe des études tibétaines est son fils aîné, Yurii Nikolaevich, dit Georges de Roerich (1902-1960), un génie des langues qui a laissé une œuvre tibétologique considérable et a réussi ce dont son père avait rêvé en vain : rentrer en URSS (grâce à Krushchev en 1957), acquérir la nationalité soviétique et faire connaître l'œuvre picturale et spirituelle de Nikolaï (on peut lire de lui, en français, le récit des grandes expéditions des Roerich, que, tout jeune homme, il a organisées et dont il a été l'interprète, à la découverte de l'Inde, des pays himalayens, du Xinjiang et de la Mongolie de 1923 à 28, Sur les pistes de l'Asie centrale, Paris, Geuthner, 1933). On le voit, le présent ouvrage s'inscrit dans tout un mouvement de pensée et de recherches propre à susciter la curiosité. Mentionnons en outre le récent et excellent volume édité encore par Dany Savelly, Le Japon en Russie : imaginaire, savoir, conflits et voyages (Slavica Occitania, XXXIII, Toulouse, 2011). 